${ }^{10}$ Ogden, M., Kellett, J. M., Merryfield, P. \& Millard, P. H. (1984) Practical aspects of automated testing of the elderly. Bulletin of British Psychological Society, 37, 148-149.

"BERGER, K. (1967) The most common words used in conversations. Journal of Communication Disorders, 1, 201-214.

${ }^{12}$ Woods, R. T. \& Britron, P. G. (1985) Clinical Psychology with the Elderly. London: Croom Helm.

${ }^{13}$ MCDONALD, C. (1969) Clinical heterogeneity in senile dementia. British Journal of Psychiatry, 115, 267-271.

${ }^{14}$ Naguib, M. \& LeVY, R. (1982) Prediction of outcome in senile dementia-a computed tomography study. British Journal of Psychiatry 140, 263-267.

\title{
Psychogeriatric Liaison A Service to a District General Hospital
}

R. M. Fraser, Consultant Psychogeriatrician, and Rosemary Healy, Registrar in Psychiatry, University College

Hospital, London

Liaison psychiatry has been an influential element in hospital psychiatric practice for over a decade now. It is concerned with the 'diagnosis, treatment, study, and prevention of psychiatric disorders among patients in nonpsychiatric health care institutions, especially in general hospitals'. ${ }^{1}$ This paper describes and evaluates a project in which the principles of liaison psychiatry were incorporated into a psychogeriatric service.

South Camden has an elderly (over 65 ) population of 15,000 , an unusually high proportion of whom (43\%) live alone. In October 1979 the consultant psychiatrists responsible for South Camden wrote to their colleagues at University College Hospital (the DGH) regretting "the vexed and growing problem of the waiting list for long-stay psychogeriatric patients". We wrote that, while we would do our best to transfer patients as speedily as possible, it seemed that "many teaching hospital wards are going to have a small number of psychogeriatric patients in residence for the foreseeable future". At that time there was a list of 33 South Camden patients awaiting admission to psychogeriatric wards, and a complicated system of priority ratings within which patients competed for beds as they became available. Eleven of these patients occupied acute hospital beds; the average waiting-time for transfer was 11.5 months.

A psychogeriatric service had been established at the beginning of 1979, and over the course of the next four years the waiting list of patients in the community was reduced until, at the time our study began in October 1983, there were no patients awaiting admission to hospital. However, the problem of 'bed-blocking' in the DGH, though it had become smaller, remained. There were never fewer than four patients awaiting transfer; at the beginning of the study, the average waiting-time was two months.

In 1983 the opportunity arose to assign an additional psychiatric trainee to psychogeriatrics for the equivalent of two sessions weekly; her primary task was that of liaison with the general wards, and it was our main hypothesis that this additional element in the service would bring about, among other benefits, a further substantial reduction in bed-blocking.

\section{Present provisions}

Medical

(i) In-patients There is a 10-bed joint geriatric/psychogeriatric unit at St Pancras Hospital (two miles from UCH) and a 27-bed acute ward at Friern Hospital (eight miles from UCH). These wards are shared equally with South Islington (elderly population 13,000). At Friern Hospital there is a 24-bed female ward and a 23-bed male ward, both for the severely demented; the male ward also receives some patients from North Camden.

(ii) Out-patients There is a twice-weekly clinic at UCH.

(iii) Day-patients There are no day facilities specifically for the elderly mentally ill, but there is a 36-place geriatric day hospital and a 30-place psychiatric day hospital on the St Pancras site, both of whom accept psychogeriatric patients if their needs warrant it. (iv) Junior staffing There is a full time $\mathrm{SHO}$ and a half-time clinical assistant based at Friern. Junior staff on the St Pancras unit are trainee physicians/geriatricians. There had been no UCH psychiatric trainee assigned to the elderly previous to this study.

Local authority

(i) Residential care There are 590 Part 3 places for Camden residents (North Camden elderly population 16,900, South Camden $15,000)$. There are no places specifically for the elderly confused. There are 25 sheltered housing units.

(ii) Day care There are two establishments specifically for the elderly. One is for a mixed group ( 100 places) and the other is for the elderly confused (45 places).

\section{Other}

A community psychiatric nurse for the elderly was appointed in 1983. At the time of the study there was no social worker for the elderly, although one has since been appointed; contact was with the ward-based social worker or with the area team. There is also direct 
contact with community-based geriatric visitors and district nurses. There is very limited access to two private homes; one is for elderly confused females. On average we would discharge about two patients annually to each.

The study population consisted of 100 consecutive referrals to the psychogeriatric service from acute (including geriatric) wards within the UCH group of hospitals. The principles of 'psychogeriatric liaison', as followed for the purposes of this study, were as follows: (1) Each patient was normally seen within $\mathbf{4 8}$ hours. As both of us were based in the DGH we were thus readily available to see or review patients at short notice, or to discuss them by phone.

(2) The psychogeriatrician's object was, where possible, to assist the staff of the acute ward with the treatment and discharge of the patient without any intervening transfer. However, the staff of a general ward cannot be expected in the longer term (for more than two to three weeks, say) to care either for patients with severe functional illness or uncomplicated senile dementia. In the former case, early transfer to an acute psychogeriatric ward was the general rule but, in the latter, what was first required was a vigorous search, with the help of social services and other disciplines, for alternatives to transfer to a 'dementia ward' in the mental hospital, partly because of all that this would entail for the patient and his relatives, and partly because, as matters stood, it would mean his name going on a waiting list. While the patient was discussed on the first visit with the referring doctor and nursing staff, there was on occasion the need for a more formal case conference that included the social worker and, usually, the patient's relatives.

(3) Even when a patient was on the waiting list he would be seen at least weekly in order to continue any treatment that had been commenced, to support staff, and for us to be aware of any change in the patient's condition.

After the last patient had been discharged or transferred from the acute ward, we reviewed all the patients.

The population The patients were aged $54-100$ (mean 78.7). There were 66 females and 34 males. They were seen over the course of 10 months ( 44.4 weeks); six were previously known to the psychogeriatric service. Fifty-eight patients were seen more than once; the number of visits to each patient ranged from one to five (mean 1.8). There were case conferences on seven patients.

The total number of referrals to the Department of Psychiatry during an overlapping, though not identical, 10-month period was 190 , suggesting that the number of psychogeriatric referrals at least equalled that of all other adult referrals.

Diagnoses Detailed figures are available from the authors. The most common psychiatric diagnoses were Alzheimer-type dementia (43), depression (30), multi-infarct dementia (10), and schizophrenic illness/paranoid state ( $($ ). There was an even spread of physical diagnoses e.g. cardiac failure (11), chest infection (9), stroke (10), carcinoma (9), fracture (9). Twenty-eight patients, however, had no physical diagnosis. The most common combination was that of dementia (clinically of Alzheimer's type) with no physical diagnosis.

Follow-up The mean period elapsing before review was six months (183 days, range 14-393). Thirty-two patients had been discharged home; 22 had died. Twenty-one had been transferred to a psychogeriatric ward; 11 had been discharged to a Part 3 Home or nursing home; eight had been transferred to geriatric wards. Two had been transferred to psychiatric wards, and the remaining four had gone to adult fostering, another hospital, a hospice and a hostel.

Waiting-time The average delay for the 24 patients who were transferred to psychogeriatric wards was 13.9 days (range 0-73). At follow-up, i.e. two weeks after the last patient had been seen, there were no patients awaiting transfer.

There were no South Camden patients awaiting admission from the community either at the beginning or the end of the study.

\section{Comment}

Waiting-lists and 'bed-blocking' are the bane of psychogeriatric practice. The result is not only inconvenience and distress for all concerned, including staff of other medical disciplines; delay is a malignant element in the psychogeriatric treatment process itself. Patients who would at one stage have been treatable may deteriorate or for other reasons become chronically dependent, so that bed occupancy increases further, and the problem feeds on itself.

Our figures indicate, first, that a district psychogeriatric service can bring about a substantial reduction in bed requirement. The list of patients awaiting admission was reduced from 33 to four over the course of four years, without any increase in the number of psychogeriatric beds; one bed was in fact taken down on the male ward to improve facilities. For comparison-in an adjacent area where there is no psychogeriatric service (North Islington: elderly population 9,000 approximately) there was at the time our own study ended (mid-August 1984) a waiting list of 45 . Of these patients 14 were occupying acute hospital beds; the average time that the in-patients had spent on the waiting list was 2.5 years.

The problem of bed-blocking has been familiar for some time to geriatricians. Studies in acute medical wards have shown that as many as one-third of the patients may be awaiting transfer to geriatric care. ${ }^{2}$ Conversely, it has been shown that schemes in which geriatricians are more closely associated with acute wards can lead to a $50 \%$ or greater reduction in length of bed occupancy by elderly patients. ${ }^{3}$ The need to extend the scope of liaison psychiatry by way of a similar association between psychogeriatricians and the acute wards has recently been emphasised in both Europe and the USA, ${ }^{1,4.5}$ but this is, as far as we know, the first evaluation of such a scheme by means of a prospective study.

The South Camden psychogeriatric service has always been DGH-based and, clearly, bed-blocking has been substantially reduced by the time the present study commenced; we suggest, however, that the final sharp drop in the figures over a relatively short period represents a virtual coup de grace delivered to the problem as a result of the extra help and the more systematic arrangements.

This was achieved, for the most part, through improved utilisation of services which were already available. These were principally:

(a) The Community Psychiatric Nursing service. A CPN for the elderly in South Camden was appointed during 1983; he meets the consultant and traince at least fortnightly.

(b) The day centre for the confused elderly. The traince was able to attend regular meetings there, and we were able 
increasingly often to refer severely confused patients who could attend five days weekly.

(c) The psychiatric day hospital. The trainee had a separate commitment there, and was able to arrange treatment of some elderly patients with functional disorder.

(d) The geriatric day hospital. More frequent visits were possible, and some of our more frail patients were able to attend following discharge. It also proved possible to treat more patients there for psychiatric symptoms without the necessity for admission.

(e) Part 3 homes. More frequent visits here were also possible, thus making it easier to have patients accepted on discharge.

The liaison service was so effective also, however, because it enabled better monitoring of patients awaiting transfer. Waiting lists are often artificially inflated as a result of poor contact between psychogeriatric and other staff. A waiting list is not a passive queue; the needs of elderly ill patients are constantly changing. One may deteriorate physically and require a different form of care, another may die, a third may (not unusually) improve, and a fourth may after all be found acceptable at home again now that an acute crisis appears to have passed. But a list made up of names of patients of whom no psychogeriatrician has day-to-day knowledge can become almost endless.

Finally, it is evident from our figures that a District General Hospital provides, and should provide, a substantial service for the local elderly mentally ill. Many such patients are admitted to its medical and surgical wards during the course of a year; for the great majority of them this is the first contact with the psychogeriatrician and, more important, most are suffering from both psychiatric and physical illness. They are, indeed, a seriously ill population and, even with the combined care of both physicians and psychiatrists, their outlook is generally bleak. In our study there was a mortality rate of $22 \%$ within six months and, although $95 \%$ had been admitted from a private address, only $32 \%$ were discharged to a private address. The life expectancy of the elderly mentally ill has increased appreciably in recent decades, ${ }^{6.7}$ and their numbers inevitably include a greater proportion of the physically ill and frail. ${ }^{8}$ The mental hospital, the traditional setting for psychogeriatric care, is thus even less appropriate than it was in the past, since these hospitals generally do not have the staff or facilities to care for a clientele which is very dependent physically. Mental hospitals tend also to be remote from the main centres of population and thus cannot offer a readily available local service; further, the very old are likely to be separated from their relatives who see themselves elderly and who may find visiting impossible. The severely demented who need continuing in-patient care will probably be best managed in centrally-located nursing homes, domestic in scale but closely associated with the acute services. The provision of two nursing homes on this model within South Camden is now part of the District Strategic Plan.

\section{REFERENCES}

'LIPOWSKI, Z. J. (1983) The need to integrate liaison psychiatry and geropsychiatry. American Journal of Psychiatry, 140, 1003-1005.

${ }^{2}$ McArdle, C., Wylie, J. C. \& Alexander, W. D. (1975) Geriatric patients in an acute medical ward. British Medical Journal, 4, 568-569.

${ }^{3}$ MCALPINE, C. J. (1979) Unblocking beds: a geriatric unit's experience with transferred patients. British Medical Journal, 2, 646-648.

4Junod, J-P. (1981) Médicine et Hygiene, 1967 à 1981. Geneva: Institutions de Gériatrie.

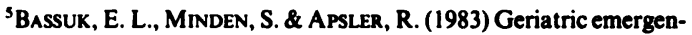
cies: physical or medical? American Journal of Psychiatry, 140, 539-542.

${ }^{6}$ BLessed, G. \& WiLson, I. D. (1982) The contemporary natural history of mental disorder in old age. British Journal of Psychiatry, 141, 59-67.

${ }^{7}$ CHRISTIE, A. B. (1982) Changing patterns of mental illness in the elderly. British Journal of Psychiatry, 140, 154-159.

${ }^{8}$ Eagles, J. M. \& Gilleard, C. J. (1984) The demented elderly admitted to a psychogeriatric assessment unit: changes in disability and outcome from 1977-82. British Journal of Psychiatry. 144, 314-316.

\section{Foundation for Gerontological Research}

To mark its centenary in 1986, Sandoz Limited, Basle, has set up the Sandoz Foundation for Gerontological Research. The aim of the Foundation is to encourage scientists to undertake new and innovative research concerned with the problems of ageing and the ageing individual. Financial assistance will be offered towards the running of particular projects. Applications will be considered by a Board of
Trustees and five regional committees worldwide. The Board is to be chaired by Professor Paul Kielholz, with Dr Hans-Peter Sigg, a member of Sandoz's Group Management, as Vice Chairman. Further information: Dr Leo Abisch, Secretary of the Sandoz Foundation for Gerontological Research, Sandoz Limited, Region III, CH-4002, Basle, Switzerland. 